\title{
A PROJECT OF LABORATORY CIRCO IN ROME: RETHINKING A PUBLIC INSTITUTES OF ASSISTANCE AND CHARITY (IPAB) IN ROME
}

DOI: $10.18485 / a r h \_p t .2020 .7 . c h 47$

\section{_ Francesco Careri}

Department of Architecture, University of Roma Tre, francesco.careri@uniroma3.it

\section{_ Fabrizio Finucci}

Department of Architecture, University of Roma Tre, fabrizio.finucci@uniroma3.it

\section{_ Chiara Luchetti}

Department of Architecture, University of Roma Tre,chi.luchetti@gmail.com

\section{_ Alberto Marzo \\ Dep. of Civil, Constructional and Environmental Engineering, Sapienza, al.marzo89@gmail.com}

\section{_ Sara Monaco}

Department of Architecture, University of Roma Tre, sara.monaco25@gmail.com

\section{_ Serena Olcuire}

Dep. of Civil, Constructional and Environmental Engineering, Sapienza, serena.olcuire@uniroma1.it

\section{_ Enrico Perini}

Department of Architecture, University of

RomaTre, enrico.perini@gmail.com

\section{_ Maria Rocco}

Department of Architecture, University of RomaTre, marimaria.rocco@gmail.com

\section{ABSTRACT}

The progressive aging of the population is a phenomenon showed by numerous researches. Several agencies and structures (public or private) are updating their legal and organizational status, in order to respond to new management methods for the provision of care and assistance services. An example in Italy is represented by the passage of Public Institutes of Assistance and Charity (IPAB) into Companies for Human Services (ASP). This transformation was addressed by the Laboratory CIRCO (an acronym for "indispensable house for civic recreation and hospitality"), active in the Architectural and Urban Design Laboratory of the master's degree program in Urban Design of the University of Roma Tre. CIRCO has investigated (thanks to a didactic planning experience) the case of an important roman IPAB, (the Istituto Romano San Michele - IRSM) which is facing a change without a complex posture, unable to combines the spaces of care with the need for temporary housing and other functions coming from the city in transformation and its new users. In particular, 
the prospects of the IRSM highlight a future scenario of a mono-functional, mono-demographic part of the city, incapable of weaving relationships of complementarity between problems and strategies. Furthermore, the existing functional and spatial quality tends to introversion, failing to open towards the neighbourhood, triggering the underutilization of some buildings, the mortification of public space and a certain relational deficiency (in some cases conflictual) among the subjects who inhabit it. The contribution deals with the first results of the CIRCO Laboratory in its attempt (through the process and the project) to transform the IPAB into an open, inclusive, hospitable and relationship-rich city.

KEYWORDS _ ageing society, hospitality, reuse, inclusive approaches

\section{INTRODUCTION}

The main world organizations have long reported that the percentage of people over sixty years old will double in 2050, reaching a third of the total population (UN, 2007 and OECD, 2005). This phenomenon will have irreparable consequences on the various social, economic and political structures and, consequently, on the organizational and spatial models of the city and on its ability to re-configure itself to the new demographic scenario (Baratta et al. 2018). Some institutions and structures that deal with third age assistance are updating their legal and organizational status, in order to respond to the new management methods of providing care and assistance services. A current example in Italy is represented by the passage of Public Institutes of Assistance and Charity (IPAB) into Companies for Human Services (ASP). The Laboratory CIRCO had the opportunity to deepen, thanks to a didactic experience held in a large Roman IPAB, the problematic picture and the possible solutions in one of these transformations. In particular, the prospects of the IPAB Roman Institute of San Michele (IRSM) show a change which is not supported by a complex posture, a posture that should be capable of combining the spaces of care with the need for temporary residentiality and other functions coming from questions posed from the transforming city and its new users.

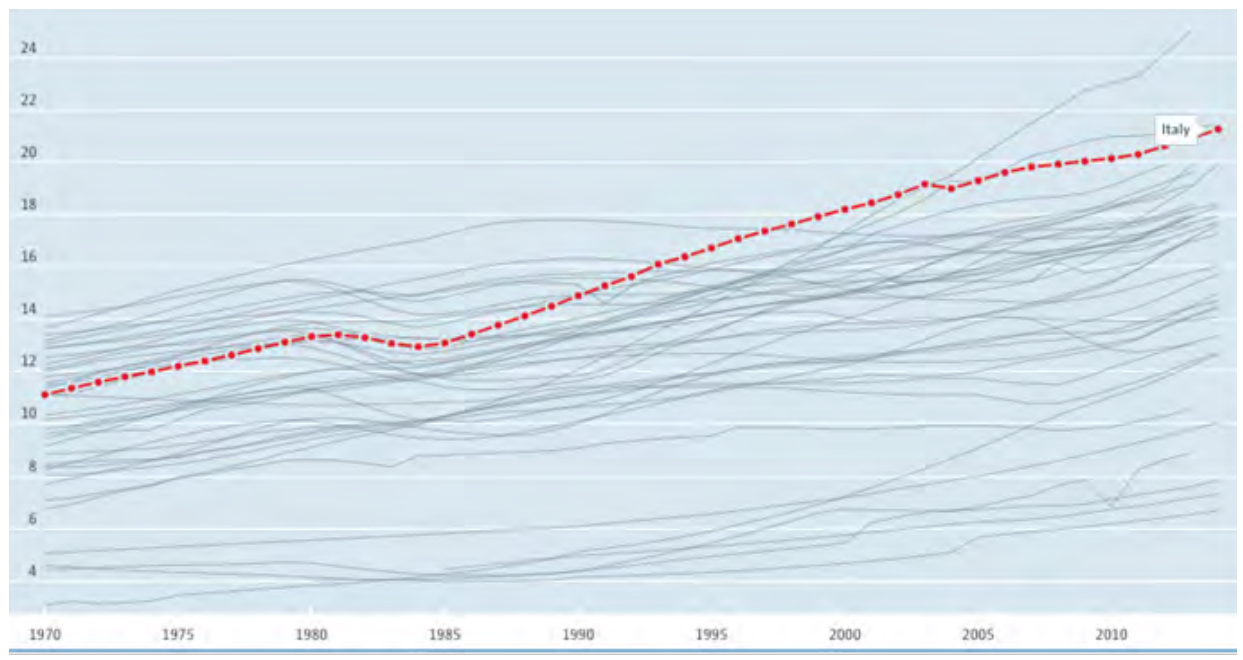

_ Fig. 1. Elderly population, percentage of population, 1970 - 2014. Source: OECD Data: https://data.oecd. org/pop/elderly-population.htm

The future scenario that appears is a piece of mono-functional, mono-demographic city, incapable 
of weaving complementary relationships between problems and strategies. Furthermore, the existing functional and spatial richness tends towards introversion, failing to open itself to the neighbourhood, triggering the underutilization of some buildings, the mortification of the public space and a relational (in some cases conflictual) deficiency among the subjects who inhabit it. With a view to an open and inclusive process, typical of the projects developed by the CIRCO Laboratory, the aim has been to fit into the existing framework of the transformation from IPAB to ASP, making unused or underutilized spaces available to new users of the city, through a spatial, economic and managerial logic that is meant to be progressive, circular and bottom up.

\section{A CASE STUDY: THE IPAB SAN MICHELE}

The history of the IPABs follows the steps of the Italian welfare since the first attempt of rationalization, sanctioned with the Law n. 6972 of 17 July 1890 (Crispi Law), which defines "assistance and charity institutions" all the pious works and any other moral entity aimed at "providing assistance to the poor". After this secularization of charity and its passage to the public sector, operated by the Crispi Law, the following step will be the Republican Constitution which will modify the charity from the benevolent approach typical of the nineteenth-century, based on the discretion of the structure about the services offered, to a system of mandatory interventions connected with the recognition to the citizen of the subjective right to social assistance, limited only by the spending policies (Corrà, 2005). Because of the establishment of the Regions, a series of regulations between 1972 and 1977 will complete the transfer of control of the IPAB from the State to the Regions. Finally, law n.328 of 2000 requires IPABs to be converted into Companies for Human Services (ASP). The ASPs retain the legal personality of the IPAB, and the same affiliation to public law in the purposes of the institution, in the absence of any profit-making, in being subject to the controls of the State authority and to its management interference. However, the ASPs act as entrepreneurial services companies, part of the integrated system of services and social welfare interventions. In this integration, always within the framework of the absence of profit, they are subject to compliance with criteria of efficiency, effectiveness and economy.

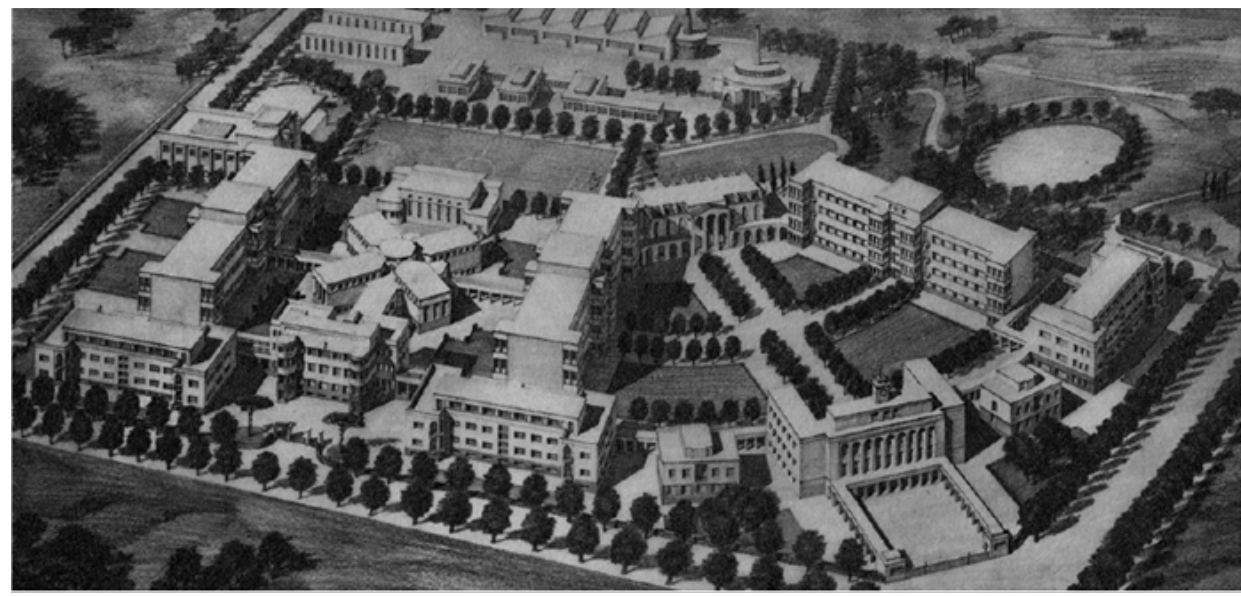

_ Fig. 2. Roman Institute of San Michele, general perspective view, source: New headquarters of the Roman Institute of S. Michele. Arch. Alberto Calza-Bini, in «Architettura», n. 5, May 1932, p. 272

The Istituto Romano San Michele (IRSM) complex, the largest Roman IPAB in terms of wealth and number of users, is located in the southern sector of the city of Rome, about $2.5 \mathrm{~km}$ from the historic centre. Today, the IPAB is completely immersed in the residential fabric of the Tor Marancia- 
Ardeatino district. The complex, originally intended for the professional and industrial training of orphans and "the needy", was designed in the 1930s and completed in 1934 (Fig. 2 and Fig. 3). Placed over an area of over 10 hectares, the main buildings are located at the intersection of the road system, following its alignment with a symmetrical and axial system that originates a central trapezoidal courtyard, overlooked by buildings that were originally used as: offices, archive, library, museum, schools, dormitories, kitchen, refectory and church (Catalano, 2011). Most of the buildings were connected by porches that crossed the large open space, characterized by the design of gardens and tree-lined paths, playgrounds and sports fields. To the original intentions of the IPABs (according to the Crispi Law) that were, "to provide assistance to the poor [...] by providing education, professional training, [...] or moral and economic improvement", the original complex responded with a system that integrated the spaces of residence, training, culture and leisure between them. This internal functional integration, however, was conceived in a strongly introverted way, aimed at a clear separation between the city and the Institute. Today the IRSM hosts several functions dedicated to assisting the elderly who will tend to increase because of the projects currently planned in the future locations (the functions currently present are shown in table 1). The IRSM therefore presents particularly evident potential, but also significant limits. The ever-growing tendency to allocate the complex to a mono-functionality of care intended as health and social care involves on the one hand the functional non-permeability of the spaces to the rest of the city (perpetuating some of the most obvious mistakes of urban-architectural culture of the last 50 years), and for the other a user with monotonous characteristics, such as a particularly advanced age and the inability to be self-sufficient in satisfying basic needs.

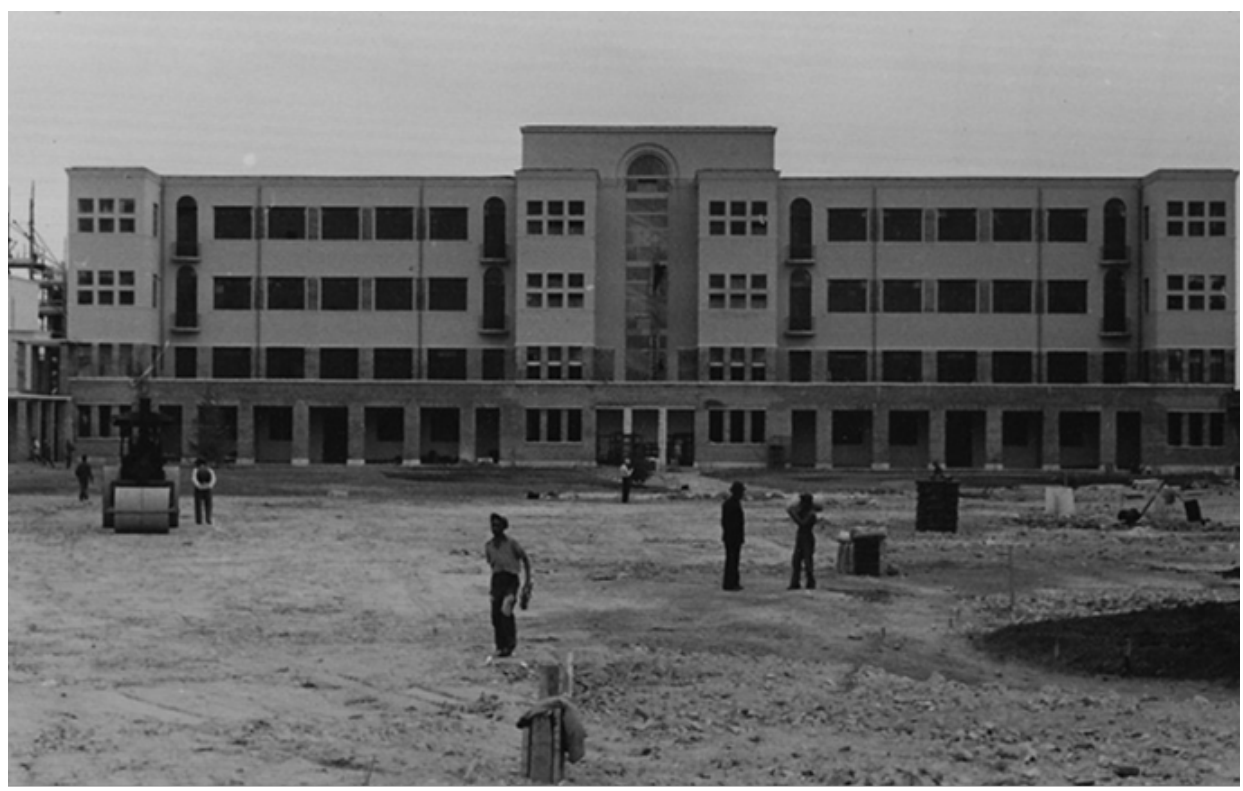

_ Fig. 3. Roman Institute of San Michele, buildings under construction, source: Alberto Calza-Bini private archive.

The infantilizing character of some forms of care implemented is evident in Italy. For example, many migrant people move away from institutional care paths not only because they feel the need to freely choose where to go to live, but also because inside the housing conditions offered by the migrant reception system, they are forced to observe forced schedules and habits, without the possibility to choose what to do or with whom to do it. These are restrictions motivated by the need to manage spaces and services in conditions of hygiene and safety, but at the same time they contribute to 
damage privacy and to infantilize adult people in their daily lives, effectively preventing the construction of any sense of home, simply providing accommodation for the satisfaction of primary needs (Squire, 2018). This approach to care is directly reflected in the management of the Institute's spaces, intended as a compartmentalized manner for the different categories of users, which, while sharing some even trivial needs (such as eating), cannot share the spaces to satisfy them.

_ Tab. 1. Buildings and functions currently present in the IRSM.

\begin{tabular}{|c|c|c|c|}
\hline Num. & $\begin{array}{l}\text { Name of the } \\
\text { building }\end{array}$ & Functions & Mq \\
\hline 1 & Offices & $\begin{array}{l}\text { Museum, entrance, IPAB offices, Local Health Authority of Rome, } \\
\text { primary assistance. }\end{array}$ & 2000 \\
\hline 2 & Toti & $\begin{array}{l}\text { Assisted living facility for elderly, cafè (unused), gym, common areas, } \\
\text { nursing home. }\end{array}$ & 4500 \\
\hline 3 & Locatelli & Totally unused. & 2400 \\
\hline 4 & Valente & Occupation (squatting) for housing purposes with common areas. & 2000 \\
\hline 5 & ex Dining Hall & $\begin{array}{l}\text { Rented to "Costumi d'Arte", a private company that deals with the } \\
\text { creation of costumes for theatre and cinema. }\end{array}$ & 2400 \\
\hline 6 & Innocenzo XII & Occupation (squatting) for housing purposes with common areas. & 2800 \\
\hline 7 & Ex Cifap & $\begin{array}{l}\text { Rented to "Emmaus" (dormitory, kitchen, soup kitchen and sales } \\
\text { rooms). }\end{array}$ & 1150 \\
\hline 8 & Liuzzi & Entirely rented to the Local Health Authority of Rome. & 4600 \\
\hline 9 & $\begin{array}{l}\text { Ex Mechanical } \\
\text { Workshop }\end{array}$ & $\begin{array}{l}\text { Work in progress by the tenant "UNISAN", a private company that } \\
\text { deals with elderly care. }\end{array}$ & 3000 \\
\hline 10 & $\begin{array}{l}\text { Church / } \\
\text { Theater }\end{array}$ & Occasionally used church and abandoned theatre. & 1100 \\
\hline 11 & Giuliani & $\begin{array}{l}\text { Community of Sant'Egidio; SPRAR (Services and housing for } \\
\text { migrants); Reception centre for migrants; Brazilian Lay Sisters } \\
\text { Community; Several unused rooms and parts. }\end{array}$ & 4500 \\
\hline 12 & Ex Gerontologic & $\begin{array}{l}\text { Intended to be rented to "UNISAN", a private company that deals with } \\
\text { assistance for the elderly. }\end{array}$ & 3000 \\
\hline 13 & $\begin{array}{l}\text { Dribbling Sport } \\
\text { Centre }\end{array}$ & Sports facilities & 300 \\
\hline 14 & Ruin & $\begin{array}{l}\text { Unfinished building of which only the structure is present; completely } \\
\text { unused. }\end{array}$ & 2000 \\
\hline
\end{tabular}

The partitioning also has a direct consequence in terms of de-qualification of the public space inside the Institute, dotted with the most varied physical and relational barriers: the subjects who inhabit the IPAB (daily or occasionally) have difficulty finding a space to meet and non-conflicting relational dimensions. The spatial richness of the complex also clashes with the non-use of an important amount of areas. Whether the spaces are used or not, in any case, the already mentioned mono-functionality of the complex and the wall that surrounds it contribute significantly to its introversion, preventing it from opening towards the neighbourhood and the city itself, which perceives it as a spatial amnesia, a void that cannot be crossed and which, after all, has no reason to be crossed. 


\section{THE CIRCO PROJECT: FROM CITY OF CARE TO CITY AS CARE}

The theme of care cannot prescind from some of the contributions coming from the feminist movements, on the one hand critically analysed as a further exclusionary patriarchal device (in the dichotomous equation that entrusts the production work to the man and that of reproduction and care to the woman), on the other claimed as an approach to act on and in the world. In this sense, some of the contributions emerged in the field of architecture and planning declines care as a form of territorial intervention, in three main aspects: a) care as a form of listening to the territories and the communities that inhabit them, paying attention to the needs, the balances and the potentialities, expressed and latent; b) care as a practice of relationships, which starting from the recognition of the other aim at creating social bonds (Poli, 2016); and C) care as a process, as an action "aimed at the improvement, the work-in-progress in a constantly evolving space, in a continuous adaptation to the needs that may arise from time to time" (Belingardi, 2015). The design indications developed for the IRSM within the 2018/2019 Architectural and Urban Design Laboratory have gone in the direction of these meanings of care, starting from the methodology with which the work was set up, physically moving the Laboratory within the Institute and thus promoting an active involvement of the group within the complex, its territory and its inhabitants. The course was characterized by events, exhibitions and collective reviews, in constant relationship with the actors of the Institute and the neighbourhood. The events were also designed and implemented in an ambitious attempt to suggest possible relationships between the actors of the Institute themselves and the related spaces, obtaining for example that the guests of the SPRAR used the kitchens of the elderly Centre to prepare a common lunch. The design proposals (fig. 4) that emerged from the Laboratory, which systematised the functional needs identified within the IPAB and at the neighbourhood level, involves four main dimensions:

_ integration of new functions, based on spaces for work (co-working), for culture (library, theatre, widespread school), for wellness services (public toilets, clinic, gym, emporium for people in economic hardship), for catering (restaurant, literary café, "pink" living room), for residences and forms of hospitality (apartments for short, medium and long term, hostel);

_ elimination of some of the physical barriers that compartmentalise the functions and their related areas, aiming at an evolution of the uncovered open space as a collector between the different realities, transforming it into a real public space permeable at urban level;

_ rethinking the categories of access to the services offered, and the consequent reorganization of the spaces: an example is the case of the residential function, which proposes a centralization of the service entrusting its management to a single body, "CIRCO Cooperative", to overcome the current compartmentalisation of the managing bodies. In this way, permanent, transient and errant users (terms that rearrange migrants, tourists, students, people needing a housing assistance and / or homelessness) can access a diversified service only according to the different length of stay;

- the implementation of circularity of resources, also for the purpose of an economic sustainability of the intervention. Each spatial and functional transformation action is accompanied by a cost / benefit feasibility plan that seeks to balance "hot" activities (which produce economic profit), "warm" activities (with moderate gains or moderate prices for some types of users) and "cold " activities (which do not produce profit, but social value). The project foresees an active role of some inhabitants in the management of the spaces, both in their maintenance and care and for their possible valorisation (economic or social) by starting work activities.

The project therefore proposes a multidimensional rethinking of care, which is not limited to a univocal vector (provider towards beneficiary user) but which, based on a reciprocal concept of hospitality, aspires to a relational process between its guests. This involves forcing the boundaries of the assistance service itself, trying instead to take on the difficult task of providing the creation of a material, social and cultural environment that allows the development of relationships of trust and mutual respect (Gill, 2018). The project proposes a change in the relational paradigm not only 
among the IPAB's users, but also between people and places themselves: in this sense, the inhabitants of IPAB can - in various forms and different degrees - activate processes of looking after the spaces of the Institute, sometimes in exchange for the same service they benefit. The rethinking of existing functions wants to expand the concept of care to the different needs of urban living and integrate health / care needs with those of education, culture, recreation, work and obviously residency.

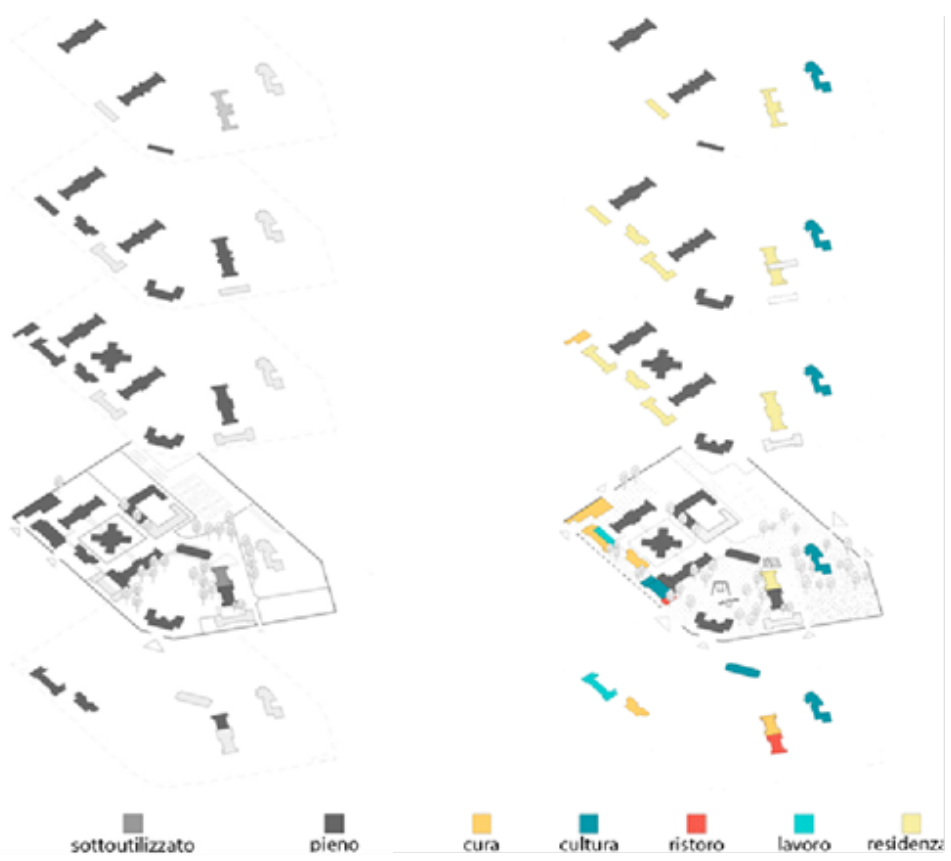

_ Fig. 4. Masterplan developed during the Lab. CIRCO

This intercepts different social segments, trying to overcome the compartmentalization suggested by many places of care (developed exclusively for the elderly or the infants or the disabled etc.): CIRCO suggests how to be together with respect to common needs, rather than dividing according to the different characteristics. The intervention aims to erode the limits that characterize the confinement of the care work: the opening of important gates in the surrounding wall of the IPAB physically and symbolically suggests the possibility of finding a new relationship with its neighbourhood and with the whole city. The proposal to integrate existing services with new cultural, recreational and convivial activities also extends the concept of care at an urban level, multiplying the possibilities of use and adapting them to the needs of the neighbourhood. Lastly, overcoming the categories of users who access the provision of care services aims to generate new forms of reciprocity and coexistence between permanent and temporary inhabitants of the city. In this sense, the dimension of care is rethought in a double correspondence with its environment: on the one hand, the IPAB extends its services by generating a care centre for the urban territory, on the other it is the urban territory to propose itself as an additional dimension of care for IPAB users, in a virtuous circular relationship.

\section{CONCLUSIONS}

What is proposed in this contribution can be considered a summary of a first approach to the theme of the re-functionalization of the IRSM, shifting its being a "city of care" to a possibility to be a form of "care of the city". This may be made through a redesign of its spaces and functions: the ISRM 
needs to mix functions concerning ageism treatment with other uses of the space (and the relative users): it is necessary to overcome the compartmentalization suggested by many places of care, and to promote their opening to rest of the city, in order to provoke a change in the relational paradigm not only among the IRSM's users, but also between people and places themselves. In relation to the CIRCO project, the main focus of this phase must necessarily be placed on the methodological path addressed both in the analysis and in the proposal phase. Having carried out the Laboratory on-site allowed a focus of the problematic picture based on direct, daily contact and in close adherence with users, operators and inhabitants of the Institute. The design process, centred on large-scale strategic choices and on relationships (spatial and relational), requires in-depth analysis and constant checks at the scale of the individual building design. In the logic with which CIRCO intends to redefine the methods of use and transformation of abandoned urban spaces, the IRSM is certainly an emblematic case of underutilization: today, in fact, it remains the clear sensation of a lost opportunity, of an underused resource that keeps a space entirely twisted around a surmountable concept of city of care which, if rethought, would have the strength and capacity to act as a cure for the city.

\section{REFERENCES}

_ Baratta, A. F. L., Farina, M., Finucci, F., Formica, G., Giancotti, A., Montuori, L., Palmieri, V. 2018. Abitazioni per Anziani. Nuove tecnologie per la fruizione dello spazio domestico. Anteferma.

- Belingardi, C. 2015. Comunanze urbane. Autogestione e cura dei luoghi. FUP, Firenze.

_ Catalano, S. 2011. Alberto Calza Bini Architetto (1881-1957). PhD Thesis in History of Architecture and Conservation of Architectural Heritage, XXI Cicle, University of Palermo, Department of Architecture.

- Corrà, D. 2005. La disciplina delle nuove IPAB. Maggioli Editore, Rimini.

_ Gill, N. 2018. The suppression of welcome. In Fennia, 196(1) pp. 88-98.

- OECD. 2005. Financial Market Trends: Ageing and Pension System Reform. Implications for Financial Markets and Economic Policies, OECD, Paris.

- Poli, D. 2016. Cartografie di genere. Disegnare il mondo con tratto di donna. In Città. Politiche dello spazio urbano. Edited by Belingardi C. and Castelli F. IAPh Italia, Roma.

_ Squire, V. 2018. Mobile Solidarities and Precariousness at City Plaza: Beyond Vulnerable and Disposable Lives. In Studies in Social Justice, vol 12, n. 1.

_ UN. 2007. World Population Ageing 2007, June 2007, United Nations, New York. 